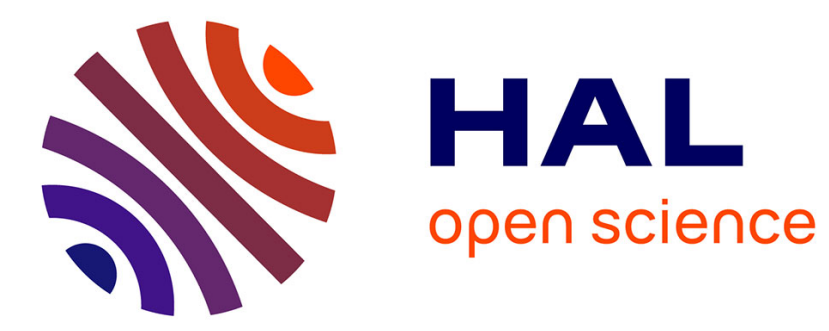

\title{
Determination of Some Complex Elastic and Electromechanical Properties of KDP
}

\author{
U. Straube, H. Beige
}

\section{To cite this version:}

U. Straube, H. Beige. Determination of Some Complex Elastic and Electromechanical Properties of KDP. Journal de Physique IV Proceedings, 1996, 06 (C8), pp.C8-437-C8-440. 10.1051/jp4:1996895 . jpa-00254706

\section{HAL Id: jpa-00254706 https://hal.science/jpa-00254706}

Submitted on 1 Jan 1996

HAL is a multi-disciplinary open access archive for the deposit and dissemination of scientific research documents, whether they are published or not. The documents may come from teaching and research institutions in France or abroad, or from public or private research centers.
L'archive ouverte pluridisciplinaire HAL, est destinée au dépôt et à la diffusion de documents scientifiques de niveau recherche, publiés ou non, émanant des établissements d'enseignement et de recherche français ou étrangers, des laboratoires publics ou privés. 


\title{
Determination of Some Complex Elastic and Electromechanical Properties of KDP
}

\author{
U. Straube and H. Beige \\ Martin-Luther-Universität Halle-Wittenberg, Fachbereich Physik, Friedemann-Bach-Pl. 6, \\ 06108 Halle/Saale, Germany
}

\begin{abstract}
The described method allows the determination of velocity and attenuation variations introduced by low frequency alternating stresses and electric fields. Uniaxial stress is produced with a high load piezoelectric actuator and controlled with a strain gauge bridge. A modified impulse echo overlap system with a computer controlled sampling oscilloscope permits the measurement of very small effects. Results for Potassium Dihydrogen Phosphate (KDP) near the phase transition at $123 \mathrm{~K}$ are presented and discussed.
\end{abstract}

\section{INTRODUCTION}

We presented a new method for the determination of elastic nonlinear coefficients in two publications [1], [2]. The aim of the present contribution is to show a further development of the measurement system. The introduction of a hardware interrupt control between sampling oscilloscope and computer allows now the simultaneous measurement of attenuation variations and changes of the velocity. First measurements were performed near the phase transition of KDP at $123 \mathrm{~K}$. Both alternating uniaxial mechanical stresses and alternating electric fields were used to introduce variations of velocity and attenuation.

\section{EXPERIMENTAL}

The principle of the mechanical apparatus for the application of uniaxial stresses is described in [2]. The force is generated by an actuator and controlled with a strain gauge bridge attached to the top of the stress apparatus. The ultrasound sample which was exposed to uniaxial stress has a sample length of $10 \mathrm{~mm}$ and lateral dimensions of $5 \mathrm{~mm}$ to achieve a nearly pure stress state. This apparatus was used for a broad temperature region down to liquid nitrogen. It was placed in liquid nitrogen dewar in its vapour phase.

The electronic setup is also explained in detail in [2]. The ultrasonic pulse method used in this experiment is similar to the method described by Korobov [3]. A computer controlled TTL-pulse generator $\mathrm{hp} 3324 \mathrm{~A}$ delivers a signal with a frequency that is approximately one hundred times higher than the inverse transit time between two ultrasound echos and is immediately divided by 100 to reduce phase noise. The master pulse is shaped following a divider $1 / 100$ and has a variable length of approximately $1 \mu \mathrm{s}$. A pulse selector consisting of a variable delay and a TTL gate produces very stable trigger pulses with a distinct delay from the master pulse. The master pulse was used to drive a fast high voltage pulse amplifier with a pulse width of 50 ns. Filters suppress higher harmonics. The impuls echo train from the ultrasound sample with a sound path length of $5 \mathrm{~mm}$ is amplified with a band pass high frequency amplifier and reaches a digital sampling oscilloscope MFA 105. This instrument has a fixed gate width of $150 \mathrm{ps}$ and worked in its initial form in a regime with a minimum fixed delay. The trigger impuls was set to a zero crossing point of one rf echo. When the external force or electric field was applied the transit time variation caused a amplitude variation of the oscilloscope output. If the signal amplitude was not dependent from the mechanical stress the 
transit time variation could be recorded.

We take the digital data from the sampling oscilloscope directly from the 12 bit AD converter and hold them in hardware latches. In this way the computer can get the data by polling. The slope of the rf curve can only be found by varying the trigger time via the pulse repetition frequency set by the TTL pulse generator if we use the polling procedure.

The modification of the setup to get the slope information directly concerns the data capture and the transfer from the sampling oscilloscope to the computer. The sampling oscilloscope is set into a true repetitive sampling regime. It takes 16 points around a zero crossing of the rf pulse with a time step of 100 ps. Every data capture causes the computer via a hardware interrupt to take the converted data point from the AD-converter. The sine period of $50 \mathrm{~ns}$ of the rf pulse is large compared to the scanned zero crossing area. Thus the zero crossing point can be found from the mean of the 16 data points and the slope gives a measure of the attenuation. We used an alternating rectangular voltage of aproximately $70 \mathrm{mHz}$ producing an uniaxial stress of the same shape. The electric field for the second experiment had also rectangular shape and was bipolar. This allows the compensation of drift effects. The signal to noise ratio was enhanced by summation of the captured data.

Two different sample orientations and arrangements were used for the investigation of the uniaxial stress dependence and the influence of an electric field on the sound propagation in KDP. Uniaxial stress was applied in the [110] direction in the first experiment. The transverse sound wave propagated in [001] and was polarized perpendicular to the stress in this case. The stress amplitude was nearly constant with an value of about $0.5 \mathrm{MPa}$.

An electric field in [001]-direction changed the properties of a transverse sound wave with a polarization along [110] in the second measurement. The electric field amplitude was varied from $780 \mathrm{~V} / \mathrm{cm}$ at $180 \mathrm{~K}$ down to $7 \mathrm{~V} / \mathrm{cm}$ near the transition point. It remained low in the ferroelectric phase.

We used quartz transducers of $20 \mathrm{MHz}$ center frequency and attached them to the sample surface with a thin layer of silicon rubber. Both cryostats were cooled in the liquid nitrogen vapour of transport dewars for biological samples with wide diameter. The temperature was controlled with a phase sensitive bridge resistor method.

\section{RESULTS AND DISCUSSION}

Figure 1 presents the result of the stress experiment. The relative velocity variation $\Delta v / v$ with the stress change $\Delta \mathrm{p}$ was very low on cooling from temperatures of $180 \mathrm{~K}$ down to $130 \mathrm{~K}$. The effect rises by the factor of 10 when the temperature of the phase transition of $123 \mathrm{~K}$ is reached. No influence of the alternating uniaxial stress on the slope of $\mathrm{rf}$ zero crossing of the echo pulses could be found. Hence the attenuation is not stress dependent in the paraelectric phase.

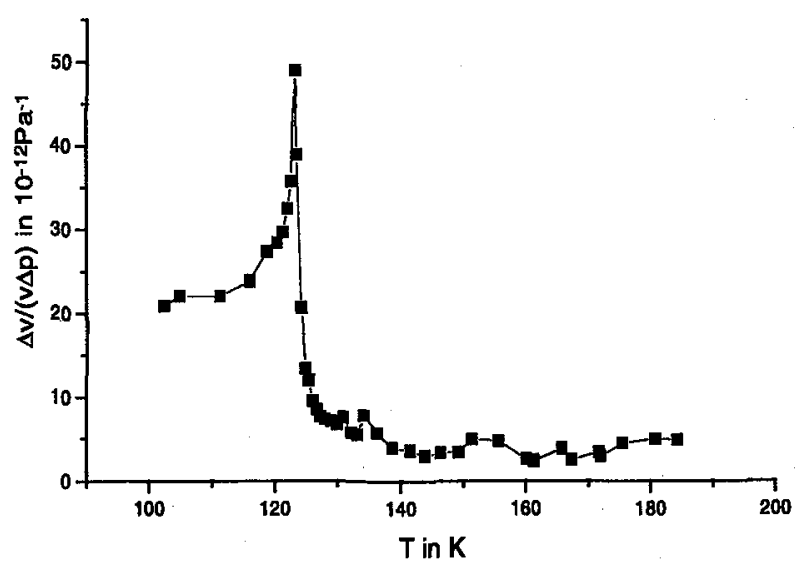

Figure 1: Temperature dependence of the velocity variation introduced by an uniaxial stress in [110]direction (transverse wave along [001], polarization perpendicular to the force) 
The velocity effect becomes smaller with decreasing temperature but remains higher than in the paraphase. We could also observe a small attenuation dependence from the stress. It was to low for quantitative use but it is shown in Figure 2 like it was measured for the temperature $118.8 \mathrm{~K}$.

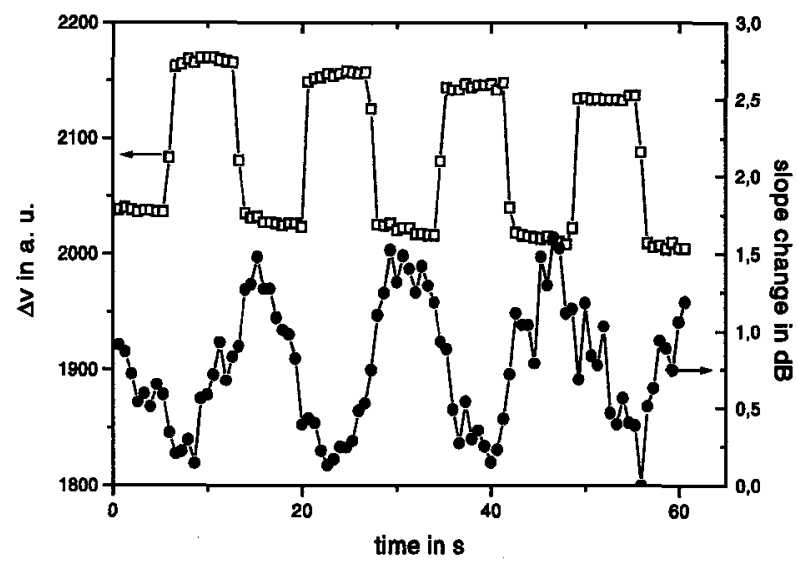

Figure 2: Measuring results of velocity and sound attenuation variations due to uniaxial stress at a temperature of $118.8 \mathrm{~K}$ (transverse wave along [001], polarization perpendicular to the force, stress in [110] direction, stress amplitude $0.44 \mathrm{MPa}$, initial slope of the used rf pulse $2.8 \mathrm{mV} / \mathrm{ns}$ )

The results of the electric field experiment are displayed in Figure 3. The relative velocity change $\Delta \mathrm{v} / \mathrm{v}$ introduced by the electric field jump $\Delta \mathrm{E}$ is nearly zero from $180 \mathrm{~K}$ to $140 \mathrm{~K}$ and increases near the transition temperature. It follows a Curie-Weiss law. This was found by one of the authors [4]. This experiment [4] could not be continued to the ferroelectric phase because pulse amplitude changes due to the alternating field disturbed the measurement [3]. This problem should be solved with the new digital principle explained in the experimental section of the present paper.

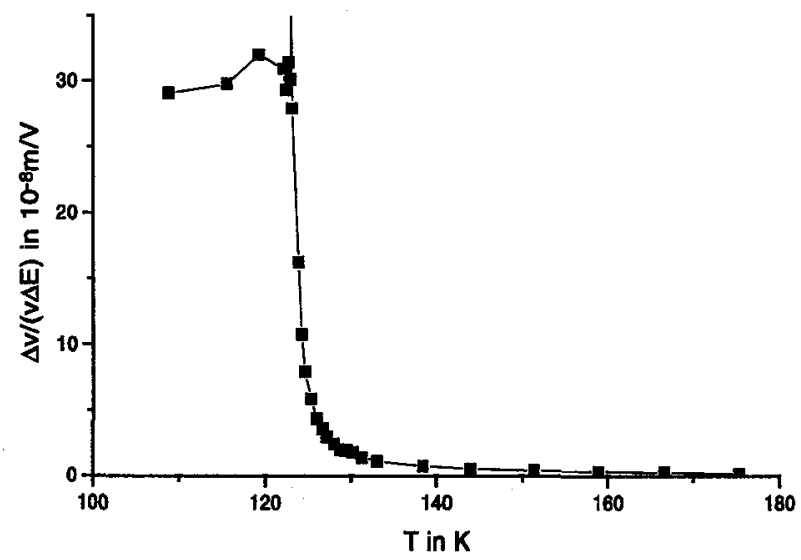

Figure 3: Temperature dependence of the velocity variation introduced by an electric field in [001]direction (transverse wave along [001], polarization along [110]) 
Unfortunately we could not find the expected strong dependence. The slope change with electric field was negligible but the velocity change had a irreversible character. The reason may be found taking in account that different KDP samples were used in the different experiments. They could have different defect concentrations, internal fields and domain structures in the ferroelectric phase. Another explanation would be the different experimental conditions. We used in the present experiment rectangular bipolar voltages of $70 \mathrm{mHz}$ frequency together with summation for noise reduction contrary to $40 \mathrm{~Hz}$ sine voltage and lock in technique in [4].

Qne measuring curve made at the temperature $91.4 \mathrm{~K}$ in the ferroelectric phase can be seen in Figure 4.

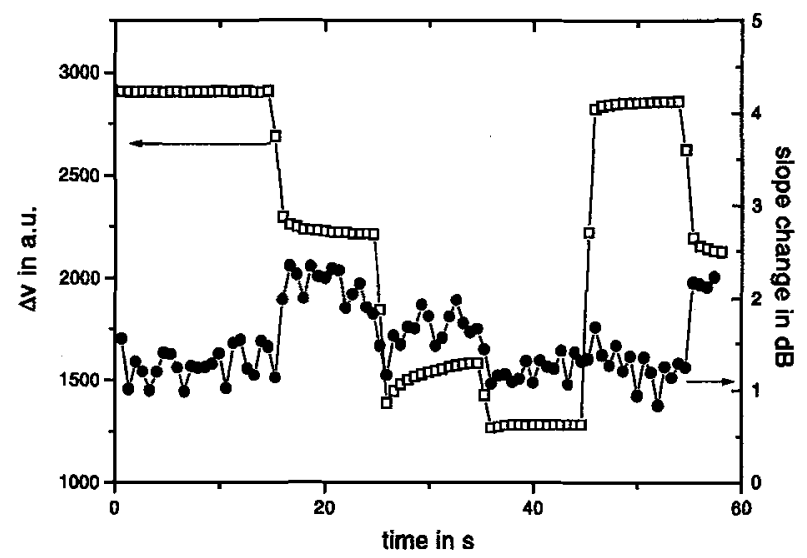

Figure 4: Measuring results of velocity changes and sound attenuation variations due to an electric field at a temperature of $91.4 \mathrm{~K}$ (transverse wave along [001], polarization in [110] direction, electric field in [001] direction, initial slope of the used $\mathrm{rf}$ pulse $2.3 \mathrm{mV} / \mathrm{ns}$, electric field stepwise varied: $+170 \mathrm{~V} / \mathrm{cm}, 0 \mathrm{~V} / \mathrm{cm},-170 \mathrm{~V} / \mathrm{cm}, 0 \mathrm{~V} / \mathrm{cm},+170 \mathrm{~V} / \mathrm{cm}, 0 \mathrm{~V} / \mathrm{cm}$ )

The field was varied stepwise like in the figure caption written. The nonlinear dependence of the sound velocity variation from the field is perhaps due to domain processes because the applied voltage was below the coercive field of approximately $1 \mathrm{kV} / \mathrm{cm}[5]$.

\section{CONCLUSIONS}

The presented improvements of the measuring system for investigations of nonlinear elastic and electromechanical effects in solids allow the simultaneous determination of ultrasound velocity and attenuation variations introduced by low frequency alternating uniaxial stresses and electric fields. Temperature dependent measurements of KDP show a strong increase of the velocity variations near the phase transition. Attenuation variations could be observed in the ferroelectric phase.

\section{REFERENCES}

[1] Straube, U. and Beige, H., Physica B 219\&220 (1996) pp 584-586.

[2] Straube, U. and Beige, H. to be published in acta physica slovaca.

[3] Korobov, A.I., Brashkin, Yu.A. and Buga, S.G., prib. i tekh. exp. 6 (1982) p 158.

[4] Straube, U., Korobov A.I, Braskin, Yu.A. and Serdobolskaya, O.Yu, acta phys. slov., 40 (1990) p 64.

[5] Barkla, H.M. and Finlayson, D.M., Phil. Mag. 44 (1953) p 109. 